\title{
CAMINO HACIA EL ÉXITO EDUCATIVO: LÍNEAS DE ACCIÓN AL PLAN CEIBAL DE URUGUAY EN VISTA AL PROGRAMA DE COMUNIDADES DE APRENDIZAJE
}

\section{A PATH TOWARDS THE EDUCATIONAL SUCCESS: ACTION LINES TO THE URUGUAYAN CEIBAL PLAN IN VIEW OF TH ELEARNING COMMUNITIES PROGRAM}

\author{
Nataly Buslón Valdez ${ }^{23}$ \\ natalybuslon@gmail.com
}

\section{Resumen}

La Sociedad de la Información y el Conocimiento trajo nuevos retos y desigualdades sociales en la población, por este motivo distintas políticas públicas fueron diseñadas con objeto de disminuir la brecha existente en materia tecnológica-educativa. En este sentido, encontramos en el mundo diversos programas orientados a aumentar el éxito educativo y la inclusión social como las Comunidades de Aprendizaje en España y el programa Plan Ceibal en Uruguay. Mediante la metodología comunicativa crítica se realiza un análisis de datos existentes, investigaciones, evaluación de políticas y distintos materiales que se han colectado para determinar nuevas líneas de acción para el Plan Ceibal en la mejora de su programa a fin de obtener una educación de éxito e inclusiva en TIC, organizando y modificando estructuras existentes.

Palabras clave: Comunidad de Aprendizaje, Plan Ceibal, éxito educativo.

\begin{abstract}
The Information and Knowledge Society brings new challenges and social inequalities to the population and therefore different public policies have been designed in order to reduce the existing gap in technology-educational matters. In this sense, we find different programs worldwide oriented to improve educational success and social inclusion such the Learning Communities in Spain the program Plan Ceibal in Uruguay. Using the critical communicative methodology, we have analyzed existing data, research, policy evaluation and other materials that have been collected to determine new lines of action for the Plan Ceibal in order to achieve a more effective and inclusive education-technologies, organizing and modifying existing structures.
\end{abstract}

Keywords: Learning Community, Plan Ceibal, educational success.

23 Investigadora predoctoral en el Departamento de Teoría Sociológica, Filosofía Derecho y Metodología de las Ciencias Sociales de la Universidad de Barcelona. Licenciada en Sociología por la Universidad de la República (Uruguay), Máster en Investigación en Sociología en la Universidad de Barcelona. Ha sido consultora del BID y asistente investigación del Ministerio de Desarrollo Social de Uruguay. Actualmente es ayudante de investigación en los proyectos IMPACT-EV (FP7, Comisión Europea) y SEAS4AIl (ERASMUS+, European Project). 


\section{INTRODUCCIÓN}

El cambio sustantivo en las tecnologías de la información y conocimiento ha afectado todos los ámbitos de la vida del hombre, incorporándose en el cotidiano social e inaugurando nuevas formas de desigualdad social. En este sentido desde el ámbito de la investigación científica, es necesario garantizar una educación de éxito ${ }^{24}$ para los niños y niñas. Trabajar junto a las familias y docentes es clave para lograr una educación, derecho humano, que mejore el nivel de aprendizaje e impacte positivamente en el desarrollo de la sociedad.

La apropiación de herramientas tecnológicas y la capacitación educativa son elementos fundamentales para poder asegurar la inclusión social y el éxito educativo en la sociedad de la información y el conocimiento. La inclusión en el mercado laboral y la participación como ciudadano, se asociará con la capacidad de poseer las habilidades intelectuales y los recursos tecnológicos relacionados en lo educativo (Gómez \& Holford, 2010).

Uruguay en esta línea, en la búsqueda de un país innovador e integrado, desarrolló distintas políticas sociales con el objetivo de brindar nuevas herramientas tecnológicas, así otorgar conocimientos para reducir la brecha digital, mejorar los niveles educativos y preparar a los ciudadanos en su inserción al mundo actual. Desde el año 2017, se desarrollaron distintos programas estatales: los Centros del Ministerio de Educación y Cultura (Centros MEC), telecentros en zonas rurales de la población que brindan cursos de informática y alfabetización digital para personas adultas y el Programa para la Conectividad Educativa de Informática Básica para el Aprendizaje en Línea (Plan Ceibal).

A través del Plan Ceibal se ha logrado democratizar para todos los estudiantes del país el uso de las herramientas informáticas, otorgando una computadora a cada niño y niña e impartiendo cursos, programas, entre otras actividades. El objetivo es disminuir las distancias entre quienes pueden y no tienen las condiciones necesarias para desenvolverse con las nuevas tecnologías. Es así que los resultados han sido sustantivos en relación a la brecha digital, con acceso total y adquisición de conocimientos básicos y manejo de los ordenadores por parte de los niños y niñas. Sin embargo, la falta de contenidos educativos que oriente el propósito de las computadoras en el aula, no ha permitido la transformación con éxito escolar, incumpliendo con una de las principales metas del Plan Ceibal, que consiste en la mejora educativa.

En esta línea, el artículo propone identificar factores que obstaculizan la mejora del sistema educativo, investigar el tiempo de capacitación de los docentes en materia tecnológica y la poca participación e integración de familiares y comunidad en el ámbito de enseñanza. A fin de determinar líneas de acción para el Plan Ceibal que beneficie el proceso de integración y la conformación de éxito en tecnología educativa en Uruguay. Para tal propósito se analizaron las actuaciones de éxito educativo de las Comunidades de Aprendizaje, revisando las condiciones necesarias para su integración al Plan Ceibal.

Investigaciones científicas a nivel mundial, destacan que el aumento de las relaciones entre escuela, familia y comunidad tiene mejoras en la educación de los niños y niñas (Harvard Family Research Project, 2006; Sheridan et al., 2005). La implicación, comunicación con las familias y la comunidad en el sistema educativo, es un componente clave para el aumento del rendimiento académico y mejor convivencia en los centros educativos (García, Duque \& Mircea, 2010). En este sentido, en las Comunidades de Aprendizaje la enseñanza es constante y compartida con la familia, es fundamental y se constata que la participación de la comunidad con los docentes, mejora la calidad de las prácticas del aula y los resultados académicos. A la vez que se desarrollan elementos preventivos a problemas sociales con resultados benéficos para el conjunto social. El modelo que se aplica corresponde a un sistema comunitario que implica que toda la población interviene en un diálogo igualitario sobre las condiciones que el grupo enfrenta para buscar solución e incluso prevenir problemas antes que aparezcan (Flecha \& García, 2007).

Partiendo de la premisa que cada contexto tiene su factor distintivo, se propone responder a la pregunta: ¿Qué condiciones presentes en el Plan Ceibal permiten implementar las actuaciones de éxito de las Comunidades de Aprendizaje? Este análisis responderá la interrogante.

24 El éxito educativo se relaciona con la finalización de la educación secundaria postobligatoria y participación en la educación terciaria superior (European Comission, 2001). 


\section{Objetivos e Hipótesis}

Se plantea que, H1) El bajo impacto en los resultados educativos en Uruguay del Plan Ceibal tiene relación inversa al alto nivel innovador, recursos destinados en materiales y formación que conlleva el programa. Esto lo determinaremos a través de la revisión de informes, evaluación y resultados del Plan Ceibal. En segundo lugar, H2) Existen suficientes recursos económicos, equipo docente, motivación de la comunidad y personal participativo en el Plan Ceibal para aplicar las actuaciones de éxito de las Comunidades de Aprendizaje. Se analizaron las condiciones de Uruguay a fin de determinar el ámbito para desarrollar actuaciones de éxito educativo.

De esta forma, se busca en este artículo a) Identificar aspectos claves del éxito en las Comunidades de Aprendizaje, b) Analizando los recursos y actuaciones que se llevan a cabo en el Plan Ceibal, a fin de c) Determinar barreras y potencialidades del Plan Ceibal en relación a las Comunidades de Aprendizaje para generar d) Líneas de actuación efectivas para la mejora del Plan Ceibal en Uruguay.

\section{METODOLOGÍA}

El enfoque de investigación aplica la metodología crítica comunicativa (MCC). Esta metodología hace énfasis en las interacciones de la vida social, centrando la dimensión de análisis en factores sociales que generan exclusión y factores de inclusión, con el objeto de transformación de la realidad social (Gómez, Puigvert, Sánchez \& Flecha, 2011). Debido a su impacto social, la metodología comunicativa es internacionalmente reconocida y recomendada por la Comisión Europea (Puigvert, 2012). La MCC se enfoca en la superación de desigualdades, a partir de la reflexión crítica y de la intersubjetividad. Dicha metodológica pretende no sólo describir y explicar la realidad estudiada, sino también comprender e interpretarla. Estudiar para transformar, haciendo hincapié en cómo se construyen los significados comunicativamente mediante la interacción entre personas (Gómez et al., 2006).

En este sentido, la MCC utiliza la acción comunicativa como orientación y construcción del diálogo en función del entendimiento entre sujetos capaces de lenguaje y acción en un proceso donde prevalecen los argumentos, en un diálogo orientado al entendimiento. En una investigación comunicativa crítica pueden utilizarse distintas técnicas cuantitativas y técnicas cualitativas, de acuerdo a los objetivos de la investigación y los datos que se quieren abordar, ya que el punto clave es utilizar la orientación comunicativa y de diálogo.

A fin de responder la pregunta de investigación y poder analizar las políticas educativas de, las Comunidades de Aprendizaje y el Plan Ceibal, se realizó una revisión documental de: informes, encuestas, evaluaciones, investigaciones y artículos indexados en bases científicas, que abordan estas temáticas hasta el año 2012. De esta forma, se recabaron 26 informes del Plan Ceibal y estudios de las Comunidades de Aprendizaje. La finalidad del análisis consistió en explicar, describir, comprender e interpretar la realidad en una investigación transformadora. Es así que se realizó una fragmentación de la información en unidades de sentido, organizando y pudiendo sintetizar los datos para facilitar la búsqueda de patrones y procesos de estudio (Latorre, Gómez \& Engel, 2010). Se determinaron tres categorías de estudio: comunidad, familia y docentes.

\section{REVISIÓN DOCUMENTAL PLAN CEIBAL - COMUNIDADES DE APRENDIZAJE}

1

Alcalde, A. Buitago, M. Castanys, M. Fálces, M. Flecha, R. (2006). Transformando la escuela: las comunidades de aprendizaje.

2 ANEP - Plan Ceibal (2011). Evaluación del Plan Ceibal 2011. Informe temático. Actividades con la XO.

3 ANEP - Plan Ceibal (2010). Informe de evaluación del Plan Ceibal 2010.

4 ANEP - Plan Ceibal (2009). Evaluación educativa del Plan Ceibal 2009.

5

6

Aristimuño, A. (2009) El Abandono de los estudios de Nivel Medio en Uruguay: Un problema complejo y persistente.

Aristimuño, A.; De Armas, G. (2012) La transformación de la educación media en perspectiva comparada. Tendencias y experiencias innovadoras para el debate en Uruguay. 


\section{REVISIÓN DOCUMENTAL PLAN CEIBAL - COMUNIDADES DE APRENDIZAJE}

8

9

10

11

12

13 Fullan, M.; Watson, N.; Anderson, S. (2013) Ceibal: Los próximos Pasos.

14 Flecha, R.; Larena, R. (2008) Comunidades de Aprendizaje. España. Fundación ECOEM.

15 Flecha, R. y García, C. Prevención de conflictos en las comunidades de aprendizaje. (2007)

16 GRUPO RADAR. ANTEL PLAN CEIBAL. (2009) El perfil del internauta uruguayo 2009.

17 y la innovación.

18 Ministerio de Educación y Cultura (2012): Anuario Estadístico de Educación 2011. CEIBAL primaria y la inclusión digital. Un estudio de casos en Uruguay.

De Armas, G. (2008) Sustentabilidad social. Reflexiones sobre la relación entre la Estrategia Nacional para la Infancia y la Adolescencia y el modelo de desarrollo de Uruguay hacia el año 2030.

Elboj, C.; Puigdellívol, I.; Soler, M.; Valls, R. (2002) Comunidades de aprendizaje. Transformar la educación.

Elboj, C.; Pulido, M.; Welikala, T. (2013) Las Tecnologías de la Información y la Comunicación en la salida del aislamiento rural: El caso de Ariño.

Ferrando, M.; Machado, A.; Perazzo, l.; Vernengo, A. (2011) Aprendiendo con las XO: El impacto del Plan Ceibal en el aprendizaje

Plan Ceibal - UNESCO (2008) Libro Verde. Ceibal en la sociedad del siglo XXI.

Plan Ceibal (2012) Evaluación Anual en Primaria 2009-2011.

Plan Ceibal (2009) Martínez, A. Alonso, S. Díaz, D. Primer Informe nacional de monitoreo y evaluación de impacto del Plan Ceibal

Plan Ceibal. (2009) Martínez, A. Alonso, S. Díaz, D. Presentación de Evaluación Anual de PLAN Racionero, S. Serradell, O. (2005) Antecedentes de las Comunidades de Aprendizaje.

Ravela, P. Pérez Gomar, G. (2012) Impactos del Plan Ceibal en las Prácticas de Enseñanza en las Aulas de Primaria.

Valls, R. (2000) Comunidades de Aprendizaje: una práctica educativa de Aprendizaje Dialógico para la Sociedad de la Información.

Wincour, R. Sánchez, R. (2012) Evaluación cualitativa de las experiencias de apropiación de las

Balsa, A.; Cid, A. (2011) Evaluación de Impacto de un Centro Educativo Gratuito y Auto-gestionado en un barrio de contexto socio-económico desfavorable de Montevideo.

Behrendt, A. (2010) Educación e Inclusión. Los procesos de enseñanza y aprendizaje en la educación computadoras XO en las familias y comunidades beneficiarias del Plan Ceibal

La revisión de la literatura y modelo de análisis se efectuó teniendo en cuenta uno de los rasgos diferenciadores de la MCC, el establecimiento de dos componentes: dimensiones exclusoras y transformadoras. Toda información relativa a prácticas y sistemas educativos segregadores, barreras que algunas personas o colectivos sociales encuentran e impiden incorporarse a un beneficio social, fueron considera dimensión exclusora. Si no existieran están barreras, las prácticas o beneficios estarían a disposición de las personas o grupos excluidos. Por el contrario, la dimensión transformadora, son elementos que contribuyen a superar barreras que impiden la incorporación de las personas y/o colectivos excluidos en distintas prácticas sociales que propician la mejora de los resultados académicos del alumnado y el éxito escolar (Gómez \& Holford, 2010). 


\section{MARCO TEÓRICO}

\section{Sociedad de la Información y el Conocimiento}

Se denomina Sociedad de la Información y el Conocimiento, a la sociedad emergente en los años setenta cuya incidencia cobra importancia a partir de los años noventa del siglo XX. Este período se destaca por la mayor relevancia y uso del conocimiento en la vida del hombre, obra de un nuevo paradigma tecnológico, que comprende el uso y evolución de las Tecnologías de la Información y el Conocimiento (TIC) y la creciente utilización y desarrollo de Internet (Castells, 2010).

Este proceso de globalización constituye un conjunto de transformaciones estéticas, culturales y económicas, caracterizado por una gama de fenómenos complejos en el ámbito global y local. Todos estos cambios son paralelos a un incremento del abismo entre los países ricos y pobres, elites ricas y mayorías empobrecidas entre regiones y zonas de un mismo territorio, ahondando en pobreza, marginación, segregación y discriminación de la población. Es así, que la brecha que se profundiza no es sólo de carácter material, sino también simbólica, ya que se determina por la desigual distribución del conocimiento y de bienes culturales, necesarios para que una sociedad pueda insertarse y sobrevivir en este mundo globalizado, altamente competitivo (Bonilla \& Cliche, 2001). Las acciones y procesos impactan de modo desigual en los individuos y sectores de la sociedad, favoreciendo a algunos, y perjudicando a otros. La globalización une al mismo tiempo que divide los grupos sociales. Como señala Bauman, lo que para algunos aparece como globalización, es localización para otros, y lejos de homogenizar la condición humana, tiende a polarizarla, ya que si bien inaugura una libertad sin precedentes, no son todos los que acceden a ella, presagia la imposibilidad de apropiarse y sobrepasar la localidad en la cual se encuentran (Bauman, 2005).

El conocimiento, en este sentido, constituye un elemento fundamental que marca la diferencia entre los individuos, influye en su éxito laboral y educativo, en el proceso de aprendizaje y desarrollo personal. Hay una descentralización del conocimiento que repercute en el cuestionamiento del conocimiento experto, el individuo hoy en día tiene la posibilidad de averiguar e indagar la realidad mediante información disponible en múltiples medios (Beck, Giddens \& Lash, 1997). La capacidad de dar sentido a la información disponible, es un elemento determinante para que la persona no quede excluida del entorno social, económico y político. La información y conocimiento es público y accesible, los niños y niñas llevan material al aula y buscan dar sentido práctico, quieren negociar y dar respuesta a lo que profesorado presenta, reflexionando a través de sus propias experiencias y consulta (Aubert et al., 2008).

De tal forma, que ir más allá del acceso, se señala como objeto principal al analizar los resultados en la educación de los niños y niñas, hacer efectiva la apropiación de las nuevas tecnologías en el proceso de enseñanza con el objeto que todos tengan la posibilidad de incorporar la información, apropiarse de datos y transformar este material de acuerdo a sus necesidades (Castells, 2003).

Más allá del contexto social económico en el que vivan los estudiantes, que no es únicamente determinante, el objetivo es lograr democratizar la información para todos los ciudadanos a través del protagonismo fundamental en los agentes sociales. La enseñanza en el aula, juega un rol importante en el proceso de aprendizaje, bajo la nueva sociedad tecnológica. No alcanza únicamente con lo que Internet nos ofrece, sino que es necesario realizar un cambio en la educación impartida, para desarrollar la capacidad de aprendizaje en una sociedad y economía basada en las redes. Se necesita desarrollar la capacidad de decidir que buscar, tener las herramientas para obtenerlo y bajo la ayuda de los docentes aprender a razonar, procesar esta información, que es lo más difícil e imprescindible para el alumnado (Castells, 2003). Los profesores deben capacitar al alumnado para utilizar eficazmente las nuevas tecnologías, se requiere un cambio en el modelo de enseñanza para adaptar sus técnicas al nuevo contexto, formando a los docentes e incorporando un nivel pedagógico adecuado para introducir nuevas habilidades de aprendizaje que transformen el modelo educativo tradicional.

Actualmente se han generado plataformas que permiten mayor acceso a todo tipo de información y conocimiento, tal como Wikipedia, la mayor enciclopedia en red gratuita, que permite acceder a gran variedad de material, siendo ejemplo del trabajo conjunto, democrático y colaborativo en el mundo interconectado, donde la información es un elemento fundamental para éxito. Los ciudadanos deben empoderarse del conocimiento, fuente de poder clara, en decisión y desarrollo en la vida de la persona, para ello, es necesario fomentar la capacidad reflexiva de los niños y niñas por parte de los docentes, sumamente importante para consolidar la apropiación y correcto desenvolvimiento en el mundo fuertemente conectado por redes 
internacionales de carácter económico, político y social. Resulta fundamental tener las herramientas y conocimientos necesarios para desarrollarse en la vida, sin determinismo social de reproducción de desigualdades, que apunte a la equidad e integración de los ciudadanos.

\section{Educación en la Sociedad de la Información y el Conocimiento}

Distintas teorías hacen referencia al modelo de desigualdad social y reproducción educativa en la sociedad presente. Cuestionan la función de la educación dentro del sistema social y plantean la posibilidad de acción, en situación de fracaso escolar y diferencia de contextos socio-económicos.

Paulo Freire plantea la idea que la educación es reflexión y acción del hombre para transformar el mundo en que vivimos, de manera tal que es el camino de liberación y la posibilidad de generar cambios en la organización social. La educación tradicional muestra instrumentos de manipulación y dominación, educar sería todo lo contrario, es hacer pensar, brindando herramientas de cambio y empoderamiento al individuo para asumir y ser partícipe del ambiente natural y social en que vive (Freire, 1976). Es fundamental crear un entorno de diálogo igualitario y de comunicación entre los actores, para lograr una apertura y participación en las distintas áreas, adquirir responsabilidad social y política sobre las condiciones presentes, una visión de un mundo no predestinado, somos seres de transformación (Freire, 2003).

Giroux realiza un cuestionamiento ininterrumpido y crítico de la realidad y de las prácticas escolares, ofrecer a los estudiantes una educación que los convierta en ciudadanos activos y críticos del mundo, no simplemente fomentar la educación en formación y capacitación para el mundo laboral. Es necesario centrar el objetivo en instruir y generar en la escuela, espacios culturales (Giroux \& Flecha, 1994).

El poder es conocimiento, el control de la información y el poder económico, están claramente relacionados. Se requiere revisar el actuar de los centros de trabajo, familia y comunidad para generar la capacidad de visualizar las relaciones sociales que reproducen históricamente formas concretas de dominación, a fin de determinar líneas de resistencia, mediante el fuerte compromiso de las prácticas educativas. La transformación sólo es posible a través de la participación en el cambio, lograr una actitud menos reduccionista y mecanicista, un agente activo, crítico y transformador del mundo (Apple, 1987). Es a través de la acción comunicativa que es posible el superar la colonización y transformar la relación del cotidiano con el sistema social. El entendimiento se basa en la teoría de la argumentación, mediante el diálogo con pretensión de validez, sin pretensión de poder oculto se podrá llegar al acuerdo. (Habermas, 1987).

De esta forma, es necesario el consenso entre los individuos, basado en la decisión de mejores acciones y razones presentadas. Las sociedades actuales tienen un carácter cada vez mayor a nivel dialógico (Flecha, Gómez \& Puigvert, 2010) y la educación en esta sociedad tiene que incluir estos diálogos entre la comunidad de expertos y la comunidad educativa concreta de la escuela.

El aprendizaje dialógico aplicado en el ámbito educativo supera las concepciones anteriores de aprendizaje como enseñanza tradicional o constructivista, desde la concepción comunicativa de la enseñanza. El objetivo de la educación es crear situaciones óptimas para que se genere el diálogo intersubjetivo en condición de igualdad y democracia entre todos los actores (García, 2010). Se pone énfasis en las interacciones sociales entre actores, más allá de las relaciones didácticas de los profesores con los alumnos, generando espacios de participación de las familias en el contexto y acción comunicativa con los distintos agentes sociales en todos los espacios de aprendizaje (Ayuste et al., 2006).

Para lograr una nueva educación y cambio social se debe estar atento, en la búsqueda de nuevas alternativas que den solución a los problemas presentes. Wright (2010) plantea, la necesidad de fomentar y reconstruir el sentido de emancipación social hacia el cambio radical de las distintas instituciones y relaciones sociales que den pasó a un mundo más igualitario, apoyar modelos innovadores de poder social y pensar en opciones emancipadoras con elementos de transformación (Wright, 2010). Las ciencias humanas pueden proponer nuevas perspectivas de sociedad, que apoyen la justicia social y política. En este sentido, la sociedad tiene el poder para establecer el control y la organización de mecánicas de funcionamiento que generen protocolos que cumplan con las necesidades sociales. El objetivo es buscar la eficiencia, evitar el desperdicio, mejorar los niveles sociales y la calidad de vida, a partir de valores que inculcamos en las acciones sociales de los individuos (Wright, 2010). 
La tarea de la sociología es brindar los elementos de análisis a los actores sociales para que puedan transformar la realidad presente, que la gente participe en las decisiones, en la proporción en la que éstas les afectan y tomen acción, adquieran un rol activo de cambio hacia la mejora de las condiciones sociales. Las Comunidades de Aprendizaje en España, son un ejemplo de empoderamiento social y participación comunitaria, son lugares educativos donde la gestión se establece por padres, profesores y miembros de la comunidad, y la función de la escuela pasa a desarrollar un valor en los niños, brindando una amplia gama de actividades de aprendizaje para la comunidad en su conjunto (Wright, 2010).

\section{Comunidades Aprendizaje}

Es importante hacer referencia a los antecedentes de las Comunidades de Aprendizaje ( $\mathrm{CdA}$ ) a fin de determinar las líneas de acción que desarrollan y de esta manera identificar aspectos claves del éxito educativo. Las Comunidades de Aprendizaje inician su proyecto en base a experiencias que tienen el reconocimiento de la comunidad científica internacional, la propuesta determinada tiene como referente las teorías y prácticas inclusoras, igualitarias y dialógicas que han demostrado tener impacto en el aprendizaje, competencia y solidaridad en los distintos contextos estudiados (Racionero \& Serradell, 2005).

Las CdA tienen como referencia proyectos con reconocido prestigio internacional en la mejora de los resultados educativos en contexto vulnerables, como la Escuela de Personas Adultas la Verneda de Sant Martí, en Barcelona (Aubert, et al., 2016), la School Development Program de la Yale University (Comer, Haynes, Joyner \& Ben-Avie, 1996), Success for All de la Johns Hopkins University (Slavin, 1996) y Accelerated Schools de Stanford University (Levin, 1993). Las actividades y el diseño de los programas superan el fracaso escolar, la conflictividad, en apoyo a las personas en situación vulnerable. En todos los proyectos, el objetivo es generar una práctica educativa transformadora, centros abiertos a la comunidad donde todas las personas y culturas son incluidas de modo igualitario. Se fundamentan en modalidades cooperativas y solidarias, rechazando la segregación y la adaptación, incluyen a las familias, profesores, alumnado y toda la comunidad (Racionero \& Serradell, 2005).

\section{Éxito de las Comunidades de Aprendizaje}

Las Comunidades de Aprendizaje ${ }^{25}$ marcan como elementos claves en el desarrollo de su proceso educativo, líneas de acción que se determinan en: diálogo igualitario, participación de la comunidad, familias y voluntariado, centralidad en el aprendizaje, expectativas positivas y progreso permanente, con el objetivo que todas las personas se enriquezcan y den sentido deseado a sus vidas (Flecha \& Larena, 2008). Es un proyecto que tiene como finalidad superar el fracaso escolar y resolver problemas de convivencia que existen en el espacio escolar. Basa su programa en actuaciones de éxito educativo (AEE) que implican a todas las personas, que de forma directa o indirecta influyen en el aprendizaje y desarrollo de los estudiantes, incluyendo profesores, familiares, amigos y amigas, vecinos y vecinos del barrio, asociaciones, organizaciones vecinales, en término general, la comunidad conjunto.

El programa cuenta actualmente con más de 120 Comunidades de Aprendizaje en España y se está desenvolviendo en Brasil, Colombia, Perú, México, Guatemala, Chile y Corea del Sur, atendiendo las necesidades de la educación infantil y educación media. Debido a su éxito, las Comunidades de Aprendizaje se han estudiado dentro del Sexto Programa Marco de Investigación de la Unión Europea INCLUD-ED, como actuación de éxito para el fomento de la cohesión social en Europa a través de la educación (Gómez \& Racionero, 2008). Dentro de las escuelas que desarrollan el modelo de las Comunidades de Aprendizaje, se destaca por parte de Microsoft, el caso del pueblo de Ariño

que comprueba el éxito educativo apoyado en el uso de las TIC, para adaptar el modelo de enseñanza a las exigencias del siglo XXI. La Comunidad de Aprendizaje de Ariño, constituye una salida del aislamiento rural en una zona desfavorecida, predestinada a la exclusión, que logra a través de este proyecto, la integración y trabajo de la comunidad, profesorado, familias, alumnos y alumnas para convertir el centro, en uno de los

25 Comunidades Aprendizaje. Sitio web: http://utopiadream.info/ca/ 
espacios educativos más avanzados en el mundo de manejo e incorporación de las TIC en el proceso de enseñanza y aprendizaje. La Comunidad de Aprendizaje de Ariño, fue reconocida por Bill Gates como modelo a seguir por la comunidad educativa por sus características de funcionamiento social, que vincula las nuevas tecnologías con la comunidad, logrando alcanzar un alto nivel de integración y colaboración entre todos los actores, que favorece el aprendizaje de los niños y niñas, con el objetivo de superar las desigualdades sociales (Elboj, Pulido \& Welikala, 2013).

En las Comunidades de Aprendizaje se desarrollan distintas AEE, que la comunidad científica internacional ha demostrado que contribuyen a mejorar los niveles de aprendizaje de los estudiantes y benefician las condiciones de convivencia dentro y fuera de los centros educativos. De esta forma, los aspectos claves de éxito educativo son: los Grupos Interactivos, Tertulias Dialógicas, Formación de Familiares, Participación educativa de la comunidad- voluntariado, Modelo dialógico de prevención y resolución de conflictos y Formación dialógica del profesorado con altas expectativas de aprendizaje. Es así que el proceso de trasformación de la escuela a Comunidades de Aprendizaje involucra estas actuaciones de éxito, en un proceso que se genera mediante la participación de toda la comunidad. ${ }^{26}$

\section{Educación en Uruguay}

Uruguay durante muchos años contó con alto nivel de cobertura y un sistema educativo privilegiado en la región. Las características claves de su vanguardia, se manifiestan por tener una educación laica, gratuita y obligatoria, tal como lo proclamó José Pedro Varela, en las diversas reformas realizadas en el año 1876. De esta forma, la educación uruguaya plantea como principio básico, la garantía de igualdad de oportunidades para todos los ciudadanos de obtener una educación gratuita hasta nivel universitario, que favorece la equidad social como deber del Estado.

En los últimos años, diversos problemas se presentan en el sistema educativo público uruguayo, que pone de manifiesto la necesidad urgente de cambio y transformación en las prácticas pedagógicas y del sistema educativo. Altas tasas de repetición en enseñanza primaria, fuerte dispersión de los rendimientos educativos manifiesta en las evaluaciones PISA y las altas tasas de deserción en los primeros años de enseñanza secundaria, estarían afectando el desempeño educativo de niños y niñas, aspecto central que repercute en exclusión social (Ferrando et al., 2011). Uruguay cuenta con un amplio nivel de cobertura de Educación Primaria ${ }^{27}$ que ha permitido alcanzar un $95 \%$ de tasa de egreso, sin embargo el panorama en educación media es completamente distinto, ubicando la tasa de graduación de Educación Media Básica en 71\% y de Educación Media Superior en 39 \%, lo que coloca a Uruguay último en el ranking de países de desarrollo humano alto del PNUD, en los países de la región. En el año 2009, el 19\% de los estudiantes de la Educación Media Básica estaba constituido por repetidores, con tendencia al alta. Mientras que en el 2000 el 23,9\% de los alumnos repitieron primer año de Educación Media Básica y en el año 2005 lo hicieron el 24,9\%, y en el 2010 la repetición para dicho grado llego a 30,2 \% registrando en Montevideo, la principal ciudad de Uruguay, un porcentaje de 42,9\% (Aristimuño \& De Armas, 2012). La baja graduación en la Educación Media en Uruguay, no se explica por la persistencia de déficit de oferta o por barreras económicas, geográficas, étnicas o raciales que impiden el acceso a los servicios, como sí sucede en otros países. Sino que los bajos niveles de egreso o graduación, revelan la elevada desafiliación del sistema educativo y la falta de capacidad del sistema, de retener a los adolescentes y lograr que avancen en su trayectoria educativa (Aristimuño \& De Armas, 2012)

Frente estas problemáticas, en el año 2005, bajo la nueva administración se inicia un proceso de debate educativo, liderado por el Ministerio de Educación y Cultura (MEC), acompañado por autoridades de la Administración Nacional de Educación Pública (ANEP). Dicho debate opero como preámbulo a la sanción de la Ley de Educación que reemplazaría la Ley de 1985. En este sentido, el nuevo gobierno de la educación, marca un rumbo sustantivo, señalando la necesidad de orientar las políticas educativas en torno a la participación, de los colectivos profesionales y la ciudadanía, consagrando cambios a través de la propuesta de la nueva Ley de Educación para todos los niveles de ámbito público y privado y educación no formal

26 Microsoft en la Educación. Sitio web: http://www.microsoft.com/education/es-es/leadership/Pages/casos-de-exito.aspx 27 La no aprobación en Primaria tiene también altos registros. Desde el año 2008 al 2011 marca aprox. 6,1\% para alumnos de 1 ero a 6to año, siendo de las más altas en América Latina (MEC, 2011). (De Armas, 2008). 
(Mancebo, 2007). Se proponen algunos programas que apuntan a la mejora de las políticas educativas del país, como el Programa de Aulas Comunitarias (PAC) y el Programa de Impulso a la Universalización (PIU). Es así que en diciembre del año 2006, el presidente Tabaré Vázquez, en búsqueda de un país integrado e innovador, anuncia que se pondrá en marcha el Programa para la Conectividad Educativa de Informática Básica para el Aprendizaje en Línea (Plan Ceibal) con el objetivo de a largo plazo promover justicia social mediante la promoción de igualdad de acceso a la información y herramientas de comunicación para todos los ciudadanos, que utilice la cultura como elemento de integración social y acceso a nuevas oportunidades de producción y trabajo (Vázquez).

\section{Plan Ceibal en Uruguay}

El Programa para la Conectividad Educativa de Informática Básica para el Aprendizaje en Línea se pone en práctica el 18 de abril del 2007 bajo el Decreto ${ }^{28}$ Presidencial 144/007 que dispone el inicio de estudios, acciones y evaluaciones necesarias para proporcionar a cada niño en edad escolar y maestros de escuela pública, una computadora portátil con el objetivo de capacitar a los docentes en el uso de la herramienta y promover la elaboración de propuestas educativas acordes. La Ley $18.640^{29}$ institucionaliza el Centro Ceibal como persona jurídica de derecho público no estatal, que responde directamente a la Presidencia de la República Oriental del Uruguay. El Centro Ceibal tiene la coordinación y desarrollo de planes y programas de apoyo a las políticas educativas de niños y adolescentes, aportando al ejercicio del derecho de la educación e inclusión social en igualdad de acceso al conocimiento y programas educativos. El Plan Ceibal se inscribe en el Programa de Equidad para el Acceso a la Información Digital (PEAID), en primera instancia se implemento a nivel de Escuela Primaria Pública y en una segunda instancia, fue extendido a la Educación Secundaria Básica y Educación Privada ${ }^{30}$.

La novedad del programa se inscribe, en que es una política TIC universal, sin sesgos de distribución por nivel socioeconómico o región ruralurbana, provee a cada niño una laptop en propiedad, que a diferencia de las estrategias basada en salas de informática, llega a los hogares, familias y comunidad en conjunto (PLAN CEIBAL, 2009a). Las computadoras (XO) fueron especialmente diseñados para el uso de los niños u niñas, tanto su hardware pequeño y resistente a golpes, como el software con una interface denominada Sugar con lógica de actividades que promueven la exploración crítica y permite el uso continuo de la XO por su alta eficiencia energética.

El Plan Ceibal combina el componente educativo, social y tecnológico en su programa, los objetivos generales son: Contribuir a la mejora de la calidad educativa mediante la integración de tecnología al aula, al centro escolar y al núcleo familiar. Promover la igualdad de oportunidades para todos los alumnos de Educación Primaria, dotando de una computadora portátil a cada niño y maestro. Desarrollar una cultura colaborativa en cuatro líneas: niño-niño, niño-maestro, maestro-maestro y niño-familia-escuela. Promover la literacidad y criticidad electrónica en la comunidad pedagógica atendiendo a los principios éticos. ${ }^{31}$

De esta forma, el Plan Ceibal busca aportar en la propuesta educativa a fin de potenciar el aprendizaje de alumnos y alumnas en el desarrollo de actitudes y destrezas en la integración de las TIC en el aula, que favorezcan el acceso a nuevos conocimientos y reflexión sobre la información que utilizan en el ámbito educativo. En la SIC, de acuerdo al planteo de Castells, la enseñanza en el aula, juega un rol importante en el proceso de aprendizaje. Es necesario realizar un cambio en la educación impartida, para desarrollar la capacidad en el niño y niña que permita desarrollar un espíritu crítico para decidir que buscar, tener las herramientas para obtenerlo y bajo la ayuda de los docentes aprender a razonar, procesar esta información, que es lo más difícil e imprescindible para el alumnado (Castells, 2003).

28 Decreto presidencial en línea: http://archivo.presidencia.gub.uy/_Web/decretos/2007/04/EC579_18\%2004\%20 2007_00001.PDF

29 Ley $N^{\circ} 18.640$ en línea: http://www.ceibal.org.uy/docs/Ley\%20creacion.pdf

30 Al año 2013. Se han otorgado 885.895 laptops: $62 \%$ Primaria, $25 \%$ Secundaria, $11 \%$ Universidad del Trabajo del Uruguay, 1,4 \% CFD (Maestros -Profesores), 0,3 \% Jardines, 0,2 \% Aulas Comunitarias y 0,4\% Centro Educativo de Capacitación y Producción (CECAP). Informe CEIBAL. Año 2013. Recuperado de http://www.ceibal.org.uy/index.php?option=com content\&view=article\&id=971:plan-ceibal-comparte-logros-en-su-qceibalometro-6-anosq\&catid=43:novedades\&ltemid=1

31 https://es.wikipedia.org/wiki/Plan_Ceibal\#Objetivos 
En esta línea, los objetivos específicos que propone el Plan Ceibal son: Promover el uso integrado del computador portátil como apoyo a las propuestas pedagógicas del aula y del centro escolar. Lograr que la formación y actualización de los docentes, tanto en el área técnica como en la pedagógica, posibiliten el uso educativo de los nuevos recursos. Producir recursos educativos con apoyo en la tecnología disponible. Propiciar la implicación y apropiación de la innovación por parte de los docentes. Generar sistemas de apoyo y asistencia técnico pedagógica específica destinada a las experiencias escolares asegurando su adecuado desarrollo. Involucrar a los padres en el acompañamiento y promoción de un uso adecuado y responsable de la tecnología para el beneficio del niño y la familia. Promover la participación de todos los involucrados en la producción de información relevante para la toma de decisiones. Propiciar la creación y desarrollo de nuevas comunidades de aprendizaje promoviendo niveles de autonomía. ${ }^{32}$

\section{Recursos y actuaciones del Plan Ceibal}

Las actuaciones de Ceibal se pueden definir en tres fases. Según Fullan, Watson y Anderson (2013), la primera etapa, cuestión de acceso, refiere desde el inicio del programa hasta el año 2009, centrando las actuaciones en proporcionar $\mathrm{XO}$ e Internet a todos los niños y niñas y maestros de educación primaria pública, posteriormente privada y secundaria pública, en la cual habría alcanzado altos logros ${ }^{33}$ (Fullan, Watson \& Anderson, 2013). El portátil ingresa al hogar con una legitimidad sustentada por distintas dimensiones: imagen del Estado como proveedor del recurso para garantizar la igualdad en los ciudadanos, apoyo positivo de los medios de comunicación que anunciaban la entrega de los ordenadores y además, la seguridad que otorgaba la figura de la escuela como actor que concede la herramienta tecnológica. En este momento el discurso dado, enfatizaba que el uso de la XO estaba destinado principalmente al niño y niña, otorgando a los padres y madres la responsabilidad del cuidado y preservación del aparato. De esta manera, mediante la presentación de documento de identidad y firma necesaria de la familia, se concedía la entrega de la XO (Winocur \& Sánchez, 2012). El Plan Ceibal se centró en brindar acceso y fueron pocos los pedagogos que participaron en el diagrama de actividades, así como también, el apoyo a usuarios estuvo dirigido básicamente a la solución de problemas técnicos (Fullan, Watson \& Anderson, 2013).

La segunda fase, se desarrolla desde el año 2010 al presente. El foco de atención se desplaza al aspecto educativo y uso pedagógico de la tecnología, desplegando múltiples recursos a fortalecer el trabajo de profesores y maestros, presionando lentamente a que se genere un cambio en las actividades del aula y dinámica del sistema educativo uruguayo. En este sentido, el Plan Ceibal cuenta con distintas acciones destinadas a la mejora de las prácticas docentes y mayor implicación de la sociedad ${ }^{34}$. Se han realizado actividades y múltiples cursos de formación, organizados y en asociación ${ }^{35}$, destacando la importante participación de distintos agentes voluntarios y asociaciones en el trabajo del Plan Ceibal, que serán analizados más adelante en la presente investigación.

De acuerdo a los informes analizados para que se genere un cambio en la dinámica de trabajo, debe desarrollarse un espíritu de colaboración y aprendizaje conjunto. Las políticas como el Plan Ceibal implementadas desde la escuela contribuyen a revertir la situación de distanciamiento del mundo escolar respecto del mundo de las nuevas tecnologías (ANEP-PLAN CEIBAL, 2010). Se observa una mejora en la autopercepción de los niños y niñas sobre el uso de los recursos, impulso en las actividades por medio de las TIC, motivación de los alumnos en el aula en participar e integrar aprendizajes, mejora de ortografía y capacidad de producir textos, fomenta el trabajo cooperativo y búsqueda y acceso a la información, desarrollo de creatividad y ayuda a alumnos con dificultades, entre otros hallazgos. Sin embargo, aún prevalecen grandes

32 https://es.wikipedia.org/wiki/Plan_Ceibal\#Objetivos

33 El acceso a nuevas tecnologías (XO) y conectividad a Internet aumento para todos los quintiles socioeconómicos (ANEP PLAN CEIBAL, 2010). Un 92\% de los Centros de Educación Inicial y Primaria tienen instalada conexión a Internet por Plan Ceibal con cobertura del $99 \%$ de los alumnos y un $99 \%$ de los alumnos de liceos de Ciclo Básico. En el 2011, el 60\% de los hogares uruguayos contaba con conectividad a Internet. (PLAN CEIBAL, 2012).

34 AprenderTod@s, Proyecto Redes Prioritarias, Espacio Ceibal, Biblioteca Digital, Olimpiada de Matemática, Mesa de Ayuda, Ceibal Móvil, Portal Ceibal, Área Formación: Cursos en Línea: Inclusión de Tecnologías en el Aula, Plataforma CREA, Maestros Dinamizadores y Maestros de Apoyo Ceibal (MAC), Área Desarrollo Comunitario, Canal Ceibal, Proyecto Robótica y Proyecto Ciencia Móvil.

35 Programa Uruguay Integra, Ministerio de Desarrollo Social, Centros Ministerio de Educación y Cultura (MEC), ONG, Fundación TELETON, entre otros. 
problemáticas, como el poco uso que le da el docente a las máquinas en el aula y escasos cambios en el modelo pedagógico (Revela \& Pérez Gomar, 2012). El cambio escolar, es necesario para romper los modelos tradicionales de educación, que como plantea Apple y Giroux es el modo para cuestionar las relaciones de poder existentes entre conocimiento y dominación (Apple, 1987; Giroux \& Flecha, 1994).

Se requiere liberar al individuo, logrando el empoderamiento social de los ciudadanos, que generen modelos alternativos a la realidad social y transformen así la línea clásica educativa, que reproduce la desigualdad social, económica y cultural (Wright, 2010). De esta manera, las TIC desvinculadas de proyectos educativos planificados, de experiencias organizadas, intenciones pedagógicas y culturales sistemáticas, tienen poca posibilidad de generar innovación con impacto social, a fin de mejorar la calidad educativa y promover la equidad social necesaria (Cabrera Paz, 2001).

Generar nuevas estrategias pedagógicas para facilitar el proceso de apropiación de la XO en los niños, adultos y comunidad. Tal como plantean Opertti y Acedo (2012), es necesaria la búsqueda de una educación inclusiva, que implique apertura, voluntad, competencias para respetar, entender apoyar y aceptar los diversos perfiles y circunstancias, contextos, necesidades de cada estudiante y comunidad, para lograr democratizar el aprendizaje, mejorando las oportunidades, procesos y resultados, en la adquisición de competencias para todos los ciudadanos. Mejorar el aprendizaje de los escolares es el objetivo central para el sistema público uruguayo, para ello es necesario conformar un proyecto claro, más allá de estrategias de transformación docente, que por sí solas no generan cambio. Ceibal se enfrenta con el desafío de lograr más apertura y nuevas ideas, busca mayor uso de las TIC en la enseñanza, mayor integración de las herramientas tecnológicas en la pedagogía y más capacidad institucional para la transformación de todo el sistema educativo, a un modelo más equitativo y de éxito.

\section{Barreras y potencialidades del Plan Ceibal en relación a las Comunidades de Aprendizaje}

La comunidad científica internacional a avalado el trabajo de las $\mathrm{CdA}$ como proyecto de éxito educativo con actuaciones que transforman la realidad recomendando implementar las AEE en Europa (European Commission, 2011) para disminuir las desigualdades, mejorando la equidad y brindando mejoras en la convivencia, resultados académicos y relaciones a nivel familiar y de la comunidad. En base a la evidencia teórica y empírica, se analizan las barreras y potencialidades del Plan Ceibal, en relación a las Comunidades de Aprendizaje determinado en cada actuación de éxito la dimensión exclusora y transformadora que se presenta en Uruguay.

\section{PRÁCTICAS EXCLUSORAS}

1. Plan Ceibal no integra agentes de cambio interesados en la política. El Plan Ceibal cuenta con un potencial muy importante en apoyo y acuerdo de la población uruguaya. El $84 \%$ de los uruguayos según la encuesta realizada en el 2009, consideró al Plan Ceibal como muy útil (Grupo Radar, 2009). Sin embargo, hay poca integración de la población en el diseño de actividades dentro del aula, desaprovechando esta dimensión.

2. Las maestras no logran integrar nuevos recursos y actividades innovadoras. No hay una conexión total en el uso de los recursos y nuevas prácticas diseñadas por el Plan Ceibal en las prácticas del aula. A pesar que la introducción de la XO, constituye una excelente oportunidad para actualizar los enfoques didácticos, es notorio cómo se mantiene fuertemente la práctica de dirigir y controlar las actividades. Los modos de trabajar constituyen una continuidad con lo que ocurría previamente en la escuela (Revela \& Pérez Gomar, 2012). Es importante contar con el compromiso docente, para la transformación educativa e impulsar nuevas acciones, de lo contrario será muy difícil generar cambio, explotar la potencialidad del programa.

3. Falta de coherencia en las medidas, coordinación de actividades, metas conjuntas. Muchas de las medidas, cursos, talleres y actividades que se han desarrollado tienen falta de coordinación. No hay suficiente seguimiento a pesar de las funciones de apoyo y recursos que el Plan Ceibal ofrece en las escuelas. Se percibe la necesidad de mejorar la precisión, coherencia y dar orientación acerca de cómo establecer una estrategia conjunta. Es poco probable que haya un cambio en la manera de enseñar y prácticas en el 
aula, por asistir simplemente a algunos cursos (Fullan, Watson \& Anderson, 2013). Resulta importante dar orientación, que facilite el proceso y evite que el profesorado se sienta agobiado por la variedad de recursos y múltiples opciones.

4. Falta de capacitación familias. Insuficiente atención por parte del Plan Ceibal. La capacitación de las familias ha sido insuficiente y poco atendida por el Plan Ceibal. Maestras y directoras reconocen que el interés de los padres por adaptarse al manejo de la XO fortalece el vínculo escuela y familia, cuestión que podría haber sido aprovechada de otra manera a efectos de lograr mayor involucramiento de las familias en el proceso educativo de sus hijos (Revela \& Pérez Gomar, 2012). El Plan Ceibal no define a la familia como destinataria, ni plantea usos familiares y colectivos. De acuerdo a la investigación de Wincour y Sánchez, algunas madres expresaron que hubieran deseado recibir formación para poder acompañar a sus hijos en el aprendizaje, así como lo hacían antes con sus tareas y actividades escolares. Si el contexto familiar es esencial para la inclusión digital y social, quizás un problema del Plan Ceibal fue el desatender la participación de la familia en el proceso de aprendizaje de las herramientas tecnológicas, que podría configurar un mejor ambiente de aprovechamiento en el hogar y usos más colectivos (Wincour \& Sánchez, 2012).

La práctica y uso de la XO quedó focalizada a los niños y niñas, manifestando resultados desiguales en la utilización de las familias según el interés, información, entendimiento y aprendizaje de cada adulto. El Gráfico 1. señala que un $84 \%$ de los familiares, manifiesta no haber participado de ninguna instancia de capacitación sobre el manejo de las XO. Sin embargo, las familias reconocen la necesidad de capacitación (ANEPPLAN CEIBAL, 2010). Si se hubiera capacitado a padres y madres de forma sistemática e ineludible, hubiera contribuido a integrar mejor a los adultos al Plan Ceibal y conocer más sobre la política desarrollada.

5. Baja relación con la familia. Falta de conexión en actividades del Plan Ceibal. El informe de evaluación del Plan Ceibal 2010, señala que se han desarrollado distintos recursos para integrar a las familias al ámbito escolar y participación en el programa: Canal Ceibal, Portal Educativo, Área Comunitaria, son algunos de los medios desarrollados. Sin embargo, el 34\% de las familias indicó no conocer la página institucional del Plan Ceibal y el $43 \%$ indicó conocerla pero no haber entrado. La propuesta de comunicación por televisión, Canal Ceibal, tampoco es conocida por un 39\% de las madres y un 22 \% admitió tener conocimiento, pero no haberlo mirado. Claramente los canales diseñados para conectar con la familia, no están siendo efectivos, las madres señalan que la mejor forma de informar respecto al Plan Ceibal, sigue siendo las reuniones en la escuela y las comunicaciones a través de cuadernos de comunicados (ANEP-PLAN CEI$B A L, 2010)$.

La Evaluación Anual en Primaria de PLAN CEIBAL (2009-2011) nos permite observar la poca información que tienen las familias sobre el plan, 19\% dice estar Nada Informadas y un 46\% manifiesta estar Poco Informadas en todos los niveles económicos de la población (PLAN CEIBAL, 2012).

6. Familias no observan transformación. No tienen control actividades del niño. La falta de conexión con el Plan Ceibal, ha llevado a que el $48 \%$ de las madres no conozca el mecanismo para saber qué páginas de Internet navego su hijo o hija. Un 32\% de los integrantes de la familia indican que no usan la XO porque no saben cómo hacerlo (PLAN CEIBAL, 2012). Al mismo tiempo, que los resultados manifiestan en un $60 \%$ la percepción de la madre sobre la igual situación ante el Plan Ceibal.

\section{PRÁCTICAS TRANSFORMADORAS}

1. Población interesada en intervenir. Para desarrollar incorporar a la dinámica educativa, una visión de cambio del sistema pedagógico, es fundamental fomentar la participación y empoderamiento social de los ciudadanos, que en Uruguay manifiestan un alto interés en el Plan Ceibal según los datos analizados. En los Grupos Interactivos es necesario contar más de un adulto en el salón de clase, para capacitar y generar espacios precisos de trabajo, que fomenten la educación de niños y niñas. Estas nuevas dinámicas de aceleración de aprendizaje, multiplican y diversifican las interacciones, mejoran la calidad del aprendizaje y benefician la convivencia a través del cambio en las pautas de trabajo educativo tradicional. Los Grupos Interactivos, logran desarrollar una nueva dinámica de aceleración de aprendizaje para el alumnado en todas las materias, valores, emociones y sentimientos de amistad entre compañeros (Alcalde et al., 2006).

2. Trabajo cooperativo. Dinámica más horizontal de intercambio del conocimiento. Hay evidencias que el trabajo cooperativo a partir del Plan Ceibal ha crecido. La dinámica de intercambio de conocimiento 
de las TIC por parte del niño y niña a maestras, directores y compañeros, ha cambiado el modelo tradicional de poder de la información a un trabajo más horizontal de intercambio de saberes (Behrendt, 2010). El caso de Nueva Helvecia, que destaca Ceibal, marca como ha sido claramente positivo el aprendizaje que han otorgado niños y niñas de sexto año de escuela a alumnos de primer año, compartiendo saberes y apoyando su formación, en un intercambio horizontal de cooperación (PLAN CEIBAL, 2009a).

Esta línea se conecta, con las dinámicas de las actuaciones de éxito desarrolladas en las Comunidades de Aprendizaje, que implican la construcción colectiva del significado mediante el intercambio de ideas y puntos de vista entre todos los participantes de forma igualitaria. Las Tertulias Dialógicas han sido objeto de investigaciones internacionales como práctica educativa innovadora por la Universidad de Harvard. Tratan la construcción colectiva del significado y conocimiento en base al diálogo e intercambio de ideas, con todo el alumnado junto a voluntarios, familiares, amigos y amigas y miembros de la comunidad que integran el proceso de aprendizaje. Consiguen sustituir interacciones de poder e imposición que se generan en entornos académicos tradicionales, por interacciones dialógicas, de comunicación libre y profunda entre los individuos para lograr una interpretación interactiva de los textos entre los niñas y niñas en el aula que rompe con el esquema de enseñanza pautado (Pulido \& Zepa, 2010).

Las Tertulias Dialógicas pueden ser de distinto tipo, literarias, musicales, de arte, matemáticas, científicas entre otras, consiste en que cada alumno participe mencionando su interpretación sobre el material trabajado, expresando a sus compañeros y compañeras lo que ha comprendido, explicando que le llamo la atención, exponiendo su reflexión crítica respecto a lo leído a través del dialogo. Se generan así, aportaciones e intercambio de ideas que es enriquecedor y permite profundizar en lo que se está estudiando, promoviendo nuevo aprendizaje y conocimientos ${ }^{36}$.

3. Caso de éxito educativo: Liceo Jubilar ${ }^{37}$. Líneas de acción en coherencia a Comunidades de Aprendizaje. El Liceo Jubilar en Uruguay, es un ejemplo de transformación del modelo tradicional de enseñanza que presenta gran compromiso de los padres en la ayuda de diversas actividades que se desarrollan en el espacio educativo. La intervención familiar es un eje de actividad, que resalta y marca impacto positivo transformador en la dinámica de trabajo. Voluntarios, adultos, y diversos miembros, colaboran en extender el horario de aprendizaje mediante actividades extra curriculares y talleres, que contribuyen a estimular el interés, fortalecer capacidades de trabajo y asentar valores en los estudiantes (Balsa \& Cid, 2011).

Este caso, muestra que en Uruguay, es posible cambiar las propuestas de trabajo establecidas, integrando dinámicas y acciones de éxito educativo, tal como Grupos Interactivos y Tertulias Dialógicas, que mejoren la calidad del aprendizaje. El Plan Ceibal presenta múltiples recursos (Olimpiadas de Matemáticas, Espacio Ceibal, Área Formación, etc.) y actividades de integración de las TIC en la práctica docente para la mejora del rendimiento académico, convivencia y nuevos conocimientos, que pueden incorporase en actuaciones de éxito, como en la Comunidad de Aprendizaje de Ariño con excelencia en uso de las TIC, anteriormente mencionada.

4. Potenciar el apoyo de las familias en el programa. Expectativas altas aprendizaje niño a partir del Plan Ceibal. Diversos estudios enfatizan que no fue aprovechado el fuerte potencial de apoyo y altas expectativas de las familias de integrar el programa y colaborar en la tarea formativa de los menores en el Plan Ceibal. Harvard Family Research Proyect desde 1983, ha estudiado cómo aumentando las relaciones familia y escuela, comunidad, se mejora la educación de niños y niñas. Las investigaciones que se han realizado marcan que el factor relevante para que estas relaciones tengan éxito, son la comunicación y las oportunidades de que las familias participen de manera formal en todos los espacios del centro educativo. (García, 2010).

De acuerdo a la Presentación de Evaluación Anual de Plan Ceibal 2009, las familias expresan que esperan un resultado mucho mejor en todos los contextos socioculturales de la escuela a partir del Plan Ceibal, lo que da un panorama positivo para la intervención familiar y para incluir su trabajo en las dinámicas educativas del centro escolar. La formación de familiares ayuda a conocer y valorar el trabajo del profesorado, potencia el aprendizaje, convivencia y el sentimiento de unión, generando una actitud positiva que repercute en la autoestima de los involucrados, aumentando la confianza y lazos entre los participantes, que mejoran los

36 Comunidades Aprendizaje. Sitio web: http://utopiadream.info/ca/?page_id=79

37 No hay registro de deserciones en el sistema educativo del Liceo Jubilar y las la tasa de repetición no alcanza el 2\% de los estudiantes, cifra que destaca en contraste al contexto de no aprobación de casi el 30\% en Ciclo Básico de los liceos de Montevideo. (MEC, 2012). 
vínculos y permite prevenir situaciones de conflicto (Alcalde et al., 2006). El panorama es positivo para el Plan Ceibal, ya que la totalidad de padres y madres manifiestan estar interesados en formarse más sobre el programa y muestran interés en participar en cursos de capacitación para comprender y ayudar a sus hijos en las actividades que desarrollan.

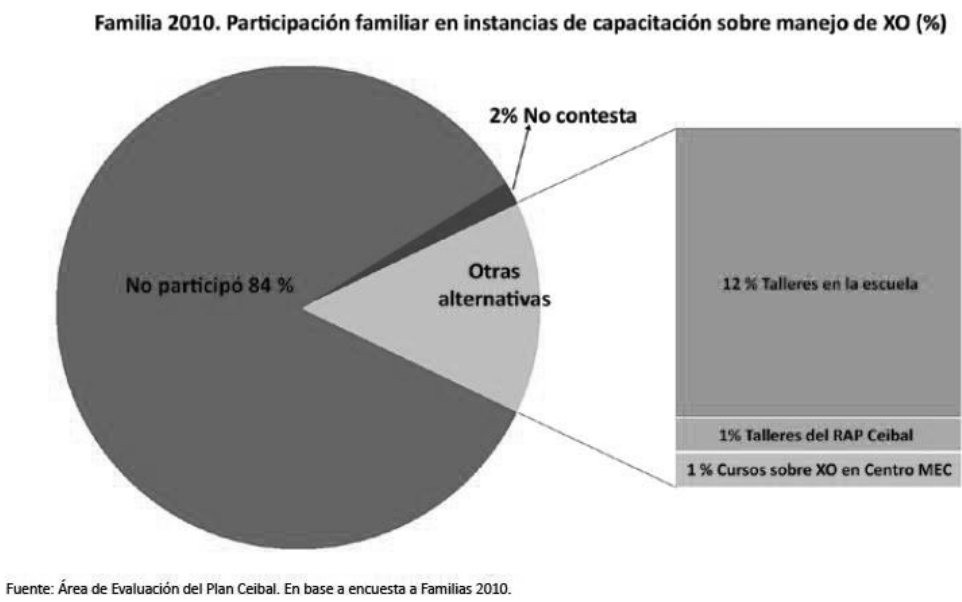

Gráfico 1.

Fuente: ANEP PLAN CEIBAL Informe de evaluación del Plan Ceibal 2010.

5. Escuela importante fuente de conexión e información sobre Plan Ceibal. Un dato importante que se destaca, es la preferencia de las familias sobre los medios para ser informados. Según los datos en la Evaluación Anual en Primaria 2009-2011, las reuniones en la escuela son para todos los sectores del país (70\%), el medio principal para conectar con las prácticas de Ceibal. La instancia de formación de familiares en las escuelas, marca un panorama positivo en predisposición a acceder a los centros educativos en búsqueda de información sobre el Plan Ceibal y manejo de las XO. Las actividades de formación que se realizan en las Comunidades de Aprendizaje están relacionadas con el acceso y procesamiento de información a través del uso de las TIC y conformación de tertulias dialógicas, así como otras actividades, con el objetivo de lograr mayor participación familiar en el ámbito educativo (Flecha \& Larena: 2008).

Diversos estudios señalan la importancia que tiene los programas de alfabetización familiar en el rendimiento académico del alumnado, padres y madres que carecen de conocimientos informáticos, a través de la formación en alfabetización digital que se desarrollan en Comunidades de Aprendizaje, como en la escuela Ariño, ayudan a sus niños y niñas a realizar deberes y otras tareas escolares, fomentando así, hábitos de estudio, aumentando la motivación y generando altas expectativas sobre el futuro educativo de sus hijos e hijas (Martínez \& Niemela, 2010).

6. Buenas prácticas Plan Ceibal confirman componente benéfico de la participación de adultos en el programa. Liceo Jubilar caso efectivo en Uruguay. Resultan positivas las buenas prácticas registradas por Plan Ceibal en: Guichón y Nueva Helvecia, son casos que destacan líneas de acción efectiva. Al programa concurren familiares de niños y niñas de contexto crítico, interesados en aprender a utilizar las XO para ayudar a sus hijos en las tareas domiciliarias, pero fundamentalmente porque sienten que se están separando de sus hijos en materia comunicacional. En este sentido, el informe del Plan Ceibal plantea que las familias perciben que el nuevo vocabulario que emplean los más jóvenes, aumenta las distancias intergeneracionales. Asimismo la participación de los adultos en el programa evidencia efectos positivos en su actuar, una maestra entrevistada destaca que una madre "...considero que podía cambiar algo de su vida y volvió a creer en que podía conseguir un trabajo. Tomó confianza porque ahora puede hacer un currículum en la XO y también sabe algo de informática" (PLAN CEIBAL, 2009a:75).

La formación de familiares en las Comunidades de Aprendizaje no sólo tiene impacto en la vida del niño y niña, sino que beneficia la vida de los adultos. Las AEE se diferencias de las buenas prácticas por ser transferibles a cualquier contexto y tener resultados positivos en el alumnado. En este sentido, generan un espacio de capacitación, mejora la autoestima y brinda la posibilidad de acceder a nuevas oportunidades en el 
mercado laboral. Son muchas las evidencias positivas, desde la mayor implicación y empoderamiento en las actividades escolares de sus hijos e hijas, hasta la mejora de la percepción personal. La familia participa en decisiones importantes que los involucra cada vez más en espacios de debate educativo, actividades, nuevos recursos y fortalece las relaciones entre miembros de la misma familia y con diferentes culturas y procedencias (Martínez \& Niemela, 2010).

En el Liceo Jubilar ha comprobado también, que integrar a los padres al centro educativo trae resultados positivos, de esta forma, se comprometen a participar en actividades de limpieza del liceo, ayuda con las comidas, integración en actividades escolares y el liceo ofrece cursos de formación para adultos en informática, cocina y deporte. Cada familia debe participar al menos en una comisión a lo largo del año, logrando apoyo total, mientras que sólo 6 de cada 10 padres en la Enseñanza Pública informa haber colaborado con el centro educativo. Asimismo se espera que haya en el hogar un adulto responsable del desempeño académico, de la evolución del estudiante y que este en comunicación con la institución (Balsa \& Cid, 2011).

\section{LÍNEAS DE ACTUACIÓN EFECTIVA PARA EL PLAN CEIBAL}

En determinación a los datos recabados, podemos observar que en los últimos años no se ha logrado reducir sustancialmente los niveles de deserción y repetición estudiantil de Primaria y Secundaria, lo que marca un panorama complejo en el sistema educativo. El Plan Ceibal muestra resultados positivos en cuanto a acceso a nuevas tecnologías y reducción de la brecha digital, sin embargo el estudio confirma la Hipótesis 1 (H1) de que su alto grado innovador, las nuevas técnicas de aprendizaje en línea, recursos destinados a capacitación docente, cursos de formación profesional en TIC y diversas actuaciones desarrolladas, no muestran impacto visible en los resultados académicos necesarios para lograr éxito educativo.

Resulta imprescindible para el Plan Ceibal determinar nuevas actuaciones de éxito educativo, para superar el acceso a tecnologías, que es importante en la SIC, pero ninguna TIC tiene impacto en el aprendizaje por sí sola, no logran potenciar la transformación educativa sin un contenido pedagógico claro y coordinado. Debe desarrollarse un razonamiento crítico de la información, como mecanismo fundamental para apropiarse de conocimientos, de acuerdo a las necesidades de cada individuo que sirva como herramienta de lucha contra la exclusión social, sobre todo en contextos desfavorables. Las TIC podrán mejorar los resultados escolares, con apoyo de nuevas líneas de trabajo, participación de familiares, voluntarios y comunidad, que en conjunto ayuden a resolver problemas prácticos de la vida diaria de niños y niñas, generen nuevas dinámicas de participación, colaboración y aprendizaje, para lograr mejores niveles educativos, resolver conflictos y problemáticas que se presentan en la comunidad.

En consideración a la Hipótesis $2(\mathrm{H} 2)$ planteada, se comprueba que existen suficientes recursos económicos, equipo docente, motivación de la población uruguaya y personal participativo en el Plan Ceibal, para aplicar las actuaciones de éxito de las Comunidades de Aprendizaje. Las condiciones analizadas en el contexto de Uruguay, marcan un amplio ámbito y flexible, que tiene como objetivo mejorar las condiciones de cada estudiante y el sistema educativo actual. En este sentido, se están realizando múltiples esfuerzos por parte de un gran equipo de investigadores, voluntarios, profesionales de diversas áreas que marcan día a día caminos y mecanismos nuevos de trabajo. Las actuaciones de éxito que desarrollan las Comunidades de Aprendizaje podrían aportar pautas más claras para vincular esos esfuerzos al éxito escolar, a la par con un empoderamiento social más fuerte de las familias y la comunidad mediante espacios dialógicos que permitan formular un sueño propio de escuela, para el futuro de los niños y niñas de Uruguay.

El Plan Ceibal se encuentra realizando un gran esfuerzo en revisar buenas prácticas que se están desarrollando en el marco de su programa, sin embargo, la diferencia entre buenas prácticas y actuaciones de éxito educativo, se encuentra en que las Comunidades de Aprendizaje aplican actuaciones que tienen sustento teórico y empírico comprobado por la comunidad científica internacional. Las actuaciones de éxito educativo, tal como la Formación de Profesorado, Participación de Familiares y Comunidad, Tertulias Dialógicas y Grupos Interactivos, son actividades que han sido analizadas en distintas partes del mundo dando como resultado la reducción de tasas de repetición, deserción, integración de la comunidad, mejor nivel académico, beneficio en la convivencia, resolución y prevención de conflictos en los centros educativos.

El análisis realizado ha permitido formular una serie de orientaciones y actuaciones para la implementación eficaz del Plan Ceibal en el sistema educativo de Uruguay. Las líneas propuestas son:

1. Incentivar la participación familiar y de la comunidad en el ámbito educativo. El Plan Ceibal tiene un potencial apoyo y aprobación de la comunidad y familia que brinda el panorama necesario para lograr 
una mayor integración en el sistema educativo. Según la información examinada, las madres sostiene que el mejor mecanismo de conexión con la escuela, son las reuniones en el centro educativo, por lo tanto, es clave incentivar la participación de los adultos y colaboración en las actividades que se desarrollan para el aprendizaje de niños y niñas, promover e intensificar las instancias colectivas de reflexión e integración en los espacios educativos.

2. Creación de Grupos Interactivos y Tertulias Dialógicas. Los Grupos Interactivos y Tertulias Dialógicas son actuaciones de éxito educativo clave para la mejora de las dinámicas de aprendizaje con alto impacto transformador de los mecanismos tradicionales de enseñanza. El trabajo en Grupos Interactivos significa una reorganización del salón de clase de forma diferente, aumentando las interacciones de ayuda mutua entre niños y niñas que están a diferentes niveles y ritmos de aprendizaje, con la ayuda de más personas adultas. Para ello, los centros educativos deberán abrirse a la entrada de nuevos profesionales y voluntariado. El acceso a la tecnología que proporciona el Plan Ceibal permite un más fácil acceso del alumnado y las familias a obras clásicas de la literatura, de la música y del arte, facilitando la puesta en marcha de Tertulias Dialógicas con los recursos ya existentes. El aprendizaje dialógico pone énfasis las interacciones igualitarias, el trabajo cooperativo de colaboración y el aprendizaje conjunto, elementos que marcan la diferencia en mejoras de la convivencia, niveles académicos y solución a problemas en la comunidad.

3. Impulso de formación docente y mayor implicación en metas del Plan Ceibal. El profesorado en la llave especial para ingresar a un nuevo mundo educativo. El Plan Ceibal debe continuar invirtiendo en la formación docente, uno de los principales obstáculos del programa, se encuentra en la falta de formación e implicación de los docentes en las metas de Ceibal. En esta nueva fase que inaugura, no se debe olvidar las demandas de apoyo y capacitación profesional. Nuevos recursos se han desarrollado, nuevas organizaciones trabajan en esta dirección, sin embargo, esta formación no debe olvidar que el empoderamiento de los docentes en el programa y la motivación en ellos, marca la diferencia en los resultados, es esencial para el buen funcionamiento, no sólo informar de mecanismos, dar cursos o talleres virtuales, sino que se necesita implicar e impulsar con entusiasmo y motivación, otorgando poder y relevancia a la tarea docente. Uruguay necesita potenciar la figura docente, importante para el cambio, todos deben implicarse, Ceibal tiene que coordinar sus actuaciones y adaptar las plataformas considerando las necesidades y escuchando todas las voces que forman parte del sistema educativo. Tal como hemos observado, muchos cursos y mecanismos implementados no son eficientes y utilizados, hay ganas motivación e incentivo, por tanto, hay que actuar antes que desaparezca.

4. Elaboración de objetivos conjunto: escuela, familia, comunidad. Habermas planteaba que todo proyecto educativo que persigue el cambio requiere del componente utópico, (Habermas, 1988) Freire afirmaba que era necesaria la formación técnica y científica, así como de sueños y utopía (Freire, 1997). Sin un objetivo ilusionante, no es posible la transformación, por tal motivo, la elaboración de sueños entre la escuela, familia y comunidad permite implicar en el movimiento a los individuos, creer en el cambio a un mundo diferente. Brindar espacio para soñar, pensar líneas de trabajo, colaboración e imaginar la escuela que deseamos lograr, es el camino para conseguir una educación igualitaria que luche contra la desigualdad social. A través de los sueños, Ceibal debe potenciar la elaboración de objetivos que incentiven el trabajo de todos los actores sociales en la transformación del centro educativo y en la mejora del sistema, brindando espacio de interacción y empoderamiento social.

5. Creación de mecanismos de coordinación y trabajo colaborativo con organizaciones y distintos actores de la sociedad civil. Uno de los aspectos que se ha observado a través de la revisión de informes e investigaciones del Plan Ceibal es la ausencia de una concreción clara de las actuaciones que se llevan a cabo con las distintas organizaciones de la sociedad civil. El Departamento de Desarrollo Social está realizando un gran trabajo con la comunidad, sin embargo, muchas organizaciones están capacitando, desarrollando actividades, brindando ayuda, talleres sin una línea general de trabajo. Se requiere diseñar planes concretos de acción, que den conexión, fuerza y coherencia a las múltiples actividades. El trabajo colaborativo y los esfuerzos de Ministerios, ONG, voluntarios etc. son importantes para el desarrollo del Plan Ceibal que desde inicios han generado un gran esfuerzo para la mejor implementación del programa. Una de las actuaciones que señalamos en el trabajo, fue la fuerte conexión del Plan Ceibal con los Centros MEC, tarea que deben profundizar, para lograr mejores resultados y eficiencia en la coordinación de las políticas. Es necesario potenciar fuerzas para concentrar el trabajo en la integración de conocimientos de TIC, pedagogía y cambio de dinámicas, que ayuden a mejorar todo el sistema, generando la energía necesaria para la transformación educativa y mejora social. 


\section{REFERENCIAS}

Aubert, A.; Flecha, A.; García, C. Racionero, S. Flecha, R. (2008). Aprendizaje dialógico en la sociedad de la información. Barcelona: Hipatia.

Aubert, A., Villarejo, B., Cabré, J., \& Tatiana Santo. (2016). La Verneda Sant Martí Adult School: A Reference for Neighborhood Popular Education. Teachers College Record, 118(4), 1-32.

Alcalde, A.; Buitago, M. Castanys, M. Fálces, M. Flecha, R. (2006) Transformando la escuela: las comunidades de aprendizaje. Barcelona: GRAO.

ANEP - Plan Ceibal (2011). Evaluación del Plan Ceibal 2011. Informe temático. Actividades con la XO. Dirección Sectorial de Planificación Educativa. Área de Evaluación del Plan Ceibal.

ANEP - Plan Ceibal (2010). Informe de evaluación del Plan Ceibal 2010. Dirección Sectorial de Planificación Educativa. Área de Evaluación del Plan Ceibal.

ANEP - Plan Ceibal (2009). Evaluación educativa del Plan Ceibal 2009. Dirección Sectorial de Planificación Educativa. Área de Evaluación del Plan Ceibal.

Apple, M. Educación y poder. Temas de educación. (1987) Barcelona: Paidós. M.E.C.

Aristimuño, A. (2009) El abandono de los estudios de nivel medio en Uruguay: un problema complejo y persistente. Revista Iberoamericana sobre Calidad, Eficacia y Cambio en Educación 7(4).

Aristimuño, A. De Armas, G. (2012) La transformación de la educación media en perspectiva comparada. Tendencias y experiencias innovadoras para el debate en Uruguay. Innovar en Educación. UNICEF.

Ayuste, A. Flecha, R. López Palma, F. Lleras, J. (2006). Planteamientos de la pedagogía crítica. Comunicar y transformar. Barcelona: Graó.

Balsa, A. Cid, A. (2011) Evaluación de Impacto de un Centro Educativo Gratuito y Auto-gestionado en un barrio de contexto socio-económico desfavorable de Montevideo. Departamento de Economía y Centro de Investigaciones Aplicadas: Pobreza, Familia y Educación. Universidad de Montevideo

Bauman, Z. (2005) Vidas desperdiciadas: La modernidad y sus parias. Barcelona, España. Paidós.

Beck, U. Giddens, A. Lash, S. (1997) Modernización reflexiva. Política, tradición y estética en el orden social moderno. Alianza Editorial.

Behrendt, A. (2010) Educación e Inclusión. Los procesos de enseñanza y aprendizaje en la educación primaria y la inclusión digital. Un estudio de casos en Uruguay. Tesis Doctoral. Universidad de Málaga. Málaga.

Bonilla, M.; Cliche, G (Eds.) (2001). Internet y sociedad en América Latina y el Caribe. Internet y sociedad en América Latina y el Caribe. Investigación para sustentar el diálogo sobre el impacto de Internet en la sociedad latinoamericana y caribeña. Quito, Ecuador. FLACSO - IDRC.

Cabrera Paz, J. (2001) Náufragos y navegantes en territorios hipermediales: experiencias psicosociales y prácticas culturales en la apropiación del internet en jóvenes escolares. En Bonilla, M.; Cliche, G (Eds). (2001). Internet y sociedad en América Latina y el Caribe. Internet y sociedad en América Latina y el Caribe. Quito, Ecuador. FLACSO - IDRC.

Castells, M. (2010) The Information Age: Economy, Society, and Culture. Volume. I. The Rise of the Network Society. U.K. Second Edition. Blackwell.

Castells, M. (2003) La divisoria digital: Una perspectiva global. La Galaxia Internet. Barcelona:Novoprint.

Comer, J., Haynes, N., Joyner, E., \& Ben-Avie, M. (1996). Rallying the Whole Village: The Comer Process for Reforming Education. Teachers College Record.

De Armas, G. (2008). Sustentabilidad social. Reflexiones sobre la relación entre la Estrategia Nacional para la Infancia y la Adolescencia y el modelo de desarrollo de Uruguay hacia el año 2030. Montevideo: Ministerio de Desarrollo Social.

Elboj, C.; Puigdellívol, I.; Soler, M.; Valls, R. (2002) Comunidades de aprendizaje. Transformar la educación. Barcelona: Graó.

Elboj, C. Pulido, M. Welikala, T. (2013) Las Tecnologías de la Información y la Comunicación en la salida del aislamiento rural: El caso de Ariño. Revista Electrónica de Geografía y Ciencias Sociales. Scripta Nova. Universidad de Barcelona.

European Commission, Dirección General de Educación y Cultura. (2001). European Report of the Quality of School Education. Sixteen quality indicators. Luxembourg. Office for Official Publications of the European Communities.

Flecha, R. Larena, R. (2008) Comunidades de Aprendizaje. España. Fundación ECOEM. 
Flecha, R; Gómez, J.; Puigvert, L (2010) teoría sociológica contemporánea. España. Paidós Studio.

Flecha, R. ; García, C. Prevención de conflictos en las comunidades de aprendizaje. (2007) Revista Idea la Mancha. Toledo, No4. pp.1-6.

Flecha, A.; García, C.; Racionero, S.; Flecha, R. (2008). Aprendizaje dialógico en la sociedad de la información. Barcelona: Hipatia.

Freire, P. (1997) A la sobra de este árbol. Barcelona: El Roure Ciencia. En Freire, P.; Macedo, D. Alfabetización Lectura de la palabra y lectura de la realidad. (1989). Barcelona: Paidós.

Freire, P. (1976). La educación como práctica de la libertad. España Editores.

Freire, P. (2003) Pedagogía del oprimido. Madrid: Siglo XXI.

Ferrando, M. Machado, A. Perazzo, I. Vernengo, A. (2011). Aprendiendo con las XO: El impacto del Plan Ceibal en el aprendizaje. Instituto de Economía. Universidad de la República. Facultad de Ciencias Económicas y de Administración. Serie Documentos de Trabajo DT 3/11Uruguay.

Fullan, M.; Watson, N.; Anderson, S. (2013). Ceibal: Los próximos Pasos. Toronto: Michael Fullan Entreprises.

García, R. (2010) Transformaciones educativas de éxito para la superación de la exclusión social: Contribuciones desde la Investigación Científica de máximo nivel Europeo. Universidad Barcelona, España.

García, R., Duque, E., \& Mircea, T. (2010). Transformación sociocultural y promoción del aprendizaje. Socio-Cultural Transformation and the Promotion of Learning, 15(2), 207-222.

Grupo Radar. ANTEL Plan Ceibal. (2009) El perfil del internauta uruguayo 2009. Séptima Edición. Montevideo, Uruguay.

Giroux, H.; Flecha, R. Igualdad educativa y diferencia cultural. (1994) Barcelona: El Roure.

Gómez, J.; Latorre, A.; Sánchez, M.; Flecha, R. Metodología Comunicativa Crítica. (2006). Barcelona: El Roure.

Gómez, A. Holford, J. (2010) Contribuciones al éxito educativo desde la metodología comunicativa. Revista Educación y Pedagogía, Medellín, Universidad de Antioquia, Facultad de Educación. 22 (56). pp. 21-29.

Gómez González, Racionero-Plaza (2008) El paradigma comunicativo crítico EEUU, University of Wisconsin. The Fourth International Congress of Qualitative Inquiry. Revista de Ciencias de la Educación. Universitat Rovira i Virgili.

Gomez, A., Puigvert, L., Sánchez, M., \& Flecha, R. (2011). Critical Communicative Methodology: Informing Real Social Transformation Through Research. Qualitative Inquiry, 17(3), 235-245.

Habermas, J. (1987). Teoría de la acción comunicativa. Vol I: Racionalidad de la acción y racionalización social. Vol II: Crítica de la razón funcionalista. Madrid. Taurus.

Habermas, J. (1988) Ensayos políticos. Madrid. Península. En: Aubert, A.; Hernández, R.; Fernández, C.; Baptista, P. (2003). Metodología de la Investigación. Chile: Mc GrawHill.

Harvard Family Research Project (2006). Family involvement in early childhood education, 1-8.

Latorre, A. ; Gómez, A.; Engel, L. Metodologia comunicativa crítica, transformació i inclusió social. (2010) Temps d’Educació, 38. pp.153 -165.Universidad de Barcelona.

Levin, H. (2000). Las Escuelas Aceleradas: Una Década de Evolución. Documentos PREAL No.18, Octubre, pp.12-13

Levin, H. (1993). The accelerated schools resource guide. San Francisco: Jossey- Bass Publishers.

Mancebo, M. E (2007). La educación uruguaya en una encrucijada: entre la inercia, la restauración y la innovación. En Bentancur, N. (Coord). Las políticas educativas en Uruguay. Perspectivas académicas y compromisos políticos. Montevideo: MEC, 2007.

Ministerio de Educación y Cultura (2012): Anuario Estadístico de Educación 2011. Área de Investigación Estadística. Dirección de Educación. Montevideo, Uruguay

Opertti, R.; Acedo, C. Educación Inclusiva: de focalizar grupos y escuelas a lograr una educación de calidad como el corazón de una Educación para Todos (EPT). (2012). En: OIE. UNESCO. La Educación para Todos de América Latina: estudios sobre las desigualdades y la agenda política en educación. Miño y Dávila.

PNUD (2006.) Informe sobre Desarrollo Humano en Chile 2006. Las Nuevas Tecnologías: ¿Un salto al futuro?. Santiago de Chile

Pulido, C. Zepa, B. (2010). La interpretación interactiva de los textos a través de las tertulias literarias dialógicas. Revista Signos. Número Especial. Monográfico №2. pp. 295-309.

Plan Ceibal - UNESCO (2008) Libro Verde. Ceibal en la sociedad del siglo XXI. 
Plan Ceibal (2012) Evaluación Anual en Primaria 2009-2011. Presentación PPT. Departamento de Monitoreo y Evolución.

Plan Ceibal (2009a) Martínez, A.; Alonso, S.; Díaz, D. Primer Informe nacional de monitoreo y evaluación de impacto del Plan Ceibal

Plan Ceibal. (2009b) Martínez, A.; Alonso, S.; Díaz, D. Presentación de Evaluación Anual de PLAN CEIBAL (2009) Monitoreo y evaluación de impacto social del Plan Ceibal

Puigvert, L. (2012). De la superstición a la ciencia : Actuaciones de éxito desde la investigación que generan transformación social. Revista Interuniversitaria de Formación del Profesorado, 73(26,1), 15-23.

Racionero, S. Serradell, O. (2005) Antecedentes de las Comunidades de Aprendizaje. Educar, 35, pp. 29 -39. ISSN: 20148801

Ravela, P. Pérez Gomar, G. (2012) Impactos del Plan Ceibal en las Prácticas de Enseñanza en las Aulas de Primaria. Universidad Católica Uruguay. University at Albany. New York. Instituto de Evaluación Educativa.

Sheridan, S. M., Clarke, B. L., Marti, D. C., Burt, J. D., \& Rohlk, A. M. (2005). Conjoint Behavioral Consultation : A Model to Facilitate Meaningful Partnerships for Families and Schools.

Slavin, R. E. (1996). Every child, every school: success for all: success for all. In Thousand Oaks. California: Corwin Press.

Valls, R. (2000). Comunidades de Aprendizaje: una práctica educativa de Aprendizaje Dialógico para la Sociedad de la Información. Universidad de Barcelona. España.

Vázquez, Tabaré. Americas Quarterly. Digital Democracy en línea. Recuperado de http://www.americasquarterly.org/ node/370

Wincour, R.; Sánchez, R. (2012) Evaluación cualitativa de las experiencias de apropiación de las computadoras XO en las familias y comunidades beneficiarias del Plan Ceibal. Universidad Católica Uruguay. Universidad Autónoma Metropolitana de México.

Wright, E. O. (2010). Envisioning Real Utopias. Nueva York: Verso. 